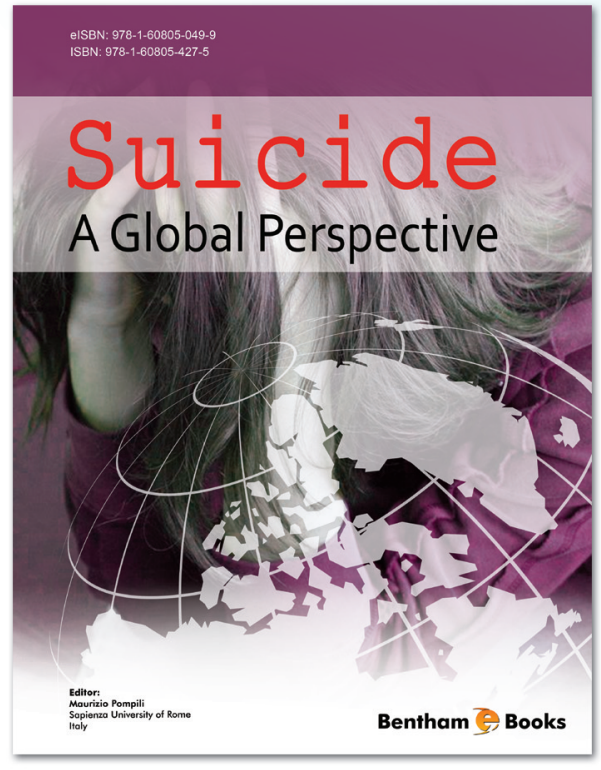

\title{
Editor:
}

Maurizio Pompili

USA

elSBN: 978-1-60805-049-9

\section{Suicide A Global Perspective}

\section{Wrw.henthamseience.60m/ehooks/9781608050499}

\section{About the ebook}

This book summarizes relevant data on suicide in countries belonging to different cultures and geographical areas. Specifically, the e-book discuses the relationship between suicide prevention agencies including government organizations; what the important issues are and what can be learned from different contests. Cultural aspects are highlighted to provide explanation for the different scenarios regarding suicide.

\section{Contents}

Assessment and Management of Suicide Risk

Culture and Suicide

- Economic Crises and Suicide

- Suicide and Alcohol Abuse

Ethnic Aspects Involved in Suicide

Spirituality, Religion and Suicide

Risk Factors for Suicide in Prisons

Psychopharmacology for Suicide Prevention

\section{For Sales Advertising Inquiries: Contact: marketing@benthamscience.org}

